\title{
Delay of reward and goal box confinement time in extinction'
}

\author{
E. J. Capaldi, UNIVERSITY OF TEXAS \\ James N. Bowen, ARLINGTON STATE COLLEGE
}

\begin{abstract}
Rats were given acquisition training in a runway under either 15- or 30-sec. constant delay of reward (10 Ss/group), terminal running time being faster for the 15-sec. group. Half of each group was extinguished under either 15- or 30-sec. goal box confinement time. A shift from $30-\mathrm{sec}$. delay to $15-\mathrm{sec}$. extinction confinement increased resistance to extinction, the opposite shift producing opposite results.
\end{abstract}

\section{Problem}

The effects of constant delay of reward on acquisition are well established, but with respect to extinction, data are scarce and somewhat inconsistent: Logan (1960) reported rate of extinction to be unaffected by acquisition delay while Fehrer (1956) found a delay group to extinguish more slowly than an immediate one. In both investigations, goal box confinement time in extinction was held constant for the different delay groups. The present investigation was concerned with the effects of both acquisition delay and extinction confinement time on extinction.

\section{Method}

The approximately 90-day old Sprague-Dawley rats were (a) divided into two groups of six males and four females each, one receiving 15-sec. delay on each of the six daily acquisition trials, the other 30-sec. delay; (b) fed mash in the home cage for $1 \mathrm{hr}$. each day; (c) handled for $1 \mathrm{hr}$. on Days 1-16; (d) allowed $5 \mathrm{~min}$. of alley exploration on Day 18; (e) given acquisition training on Days 19-25 and extinction training (also six trials/day) on Days 26-28, the intertrial interval being $1 \mathrm{~min}$. Matched halves of Group 30 and Group 15 were extinguished under either 15-sec. or 30-sec. goal box confinement. In extinction, groups are designated on the basis of two numbers, i. e., Group 30-15 was given 30sec. acquisition delay and 15-sec. extinction confinement. Failure to enter the goal box within $90 \mathrm{sec}$. resulted in forcing in acquisition and removal from the runway in extinction, a time score of 90 sec. being recorded.

The mid-gray apparatus consisted of a 90-in long and 4 -in wide runway with $81 / 2$-in high sides and an automatically operated, metal food cup (11/2 x $11 / 4 \times 1$ in). The .01 timer was started by placing $S$ on a 10 -in start treadle and stopped when $S$ interrupted a photobeam $31 / 2$ in from the alley's end. In acquisition, a sliding lid, covering the mash-filled food cup, opened either 15 or $30 \mathrm{sec}$. after the photobeam was broken, always closing $15 \mathrm{sec}$. thereafter. The $S$ was then removed from the goal box to await the next trial or, following Trial 6 , was returned to the home cage where it was fed about 15 min. later. In extinction, the food cup remained open and unbaited. A guillotine door 12 in from the rear of the goal box was lowered manually when $\mathrm{S}$ broke the photobeam.

\section{Results}

As Fig. 1 shows, by the end of acquisition training Group 15 was considerably faster than Group 30, differences employing the mean of the logs on the last three days being highly significant $(F=18.95$, df $1 / 18$, $\mathrm{P}<.005)$. In acquisition, Group 30 became only slightly faster over days, a finding reasonably consistent with results reported by Logan (1960) for 30-sec. delay in the runway.

Immediately obvious in Fig. 1 is that in extinction 15-sec. confinement produced faster running than 30sec. and Group 30-15 showed no tendency to slow up over days. A repeated-measures analysis on the extinction means indicated significant differences for groups $(F=4.66$, df $3 / 16, P<.05)$, days $(F=4.08$, df $2 / 32$, $\mathrm{P}<.05)$, and the interaction of groups $\mathrm{x}$ days $(\mathrm{F}=2.58$, df $6 / 32, P<.05)$. Consistent with the repeated-measures analysis were the results of factorial analyses applied to each day of extinction; on Days 1 and 2 only extinction confinement was significant $(\mathrm{F}=6.35$ and 13.74, $\mathrm{P}<.05$ and .005 , respectively) while by Day 3 extinction confinement $(\mathrm{F}=13.88, \mathrm{P}<.005)$, acquisition delay $(F=4.68, P<.05)$, and the interaction of extinction confinement $\mathrm{x}$ acquisition delay $(\mathrm{F}=4.89$,

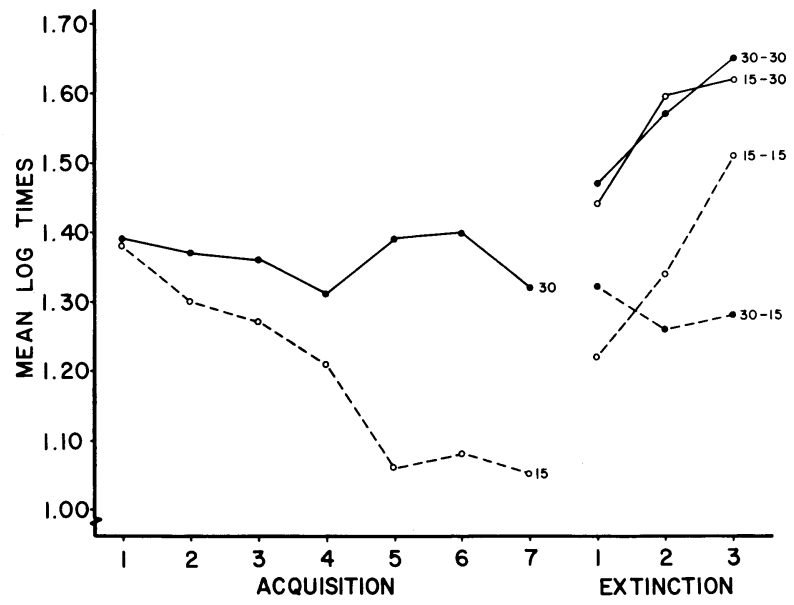

Fig. 1. Mean log running time on each day of acquisition and extinction for each of the groups. 
$\mathrm{P}<.05)$ were all significant ( $\mathrm{df}=1 / 16$ in all cases).

\section{Diseussion}

The very considerable resistance to extinction of the 30-15 group seems compatible with the $r_{g}$ analysis of Logan (1960). On the whole, the results indicate that resistance to extinction increases as acquisition delay increases, a finding which is more consistent with Fehrer's (1956) results than with Logan's (1960). However, the generality of this finding is limited by the fact that the 15-30 group showed decreased resistance to extinction only with respect to the 15-15 group and not the 30-30 group. In view of the extinction performance of Group 30-15, why did not Group 15-30 run slower in extinction than Group 30-30? One possibility is that $30 \mathrm{sec}$. of extinction confinement produces such slow running that little opportunity existed for Group 15-30 to run any slower than it did. For example, on Days 2 and 3 of extinction, over $25 \%$ of $15-30$ 's extinction trials were $90 \mathrm{sec}$. or removal trials. Possibly, then, smaller shifts, i. e., from 10 to 15 or $20 \mathrm{sec}$. might well produce results showing a greater effect attributable to acquisition delay. As the preceding suggests, extinction confinement is a quite powerful variable, resistance to extinction decreasing in this investigation as extinction confinement increased. Not only was this the clearest finding in the present investigation but one which is in complete accord with the results reported by Stanley \& Rowe (1954) and, provided very short confinement times are excluded, with the results of Klugh (1961). Both investigations employed immediate reward in acquisition.

\section{References}

FEHRER, E. Effects of amount of reinforcement and of pre- and postreinforcement delays on learning and extinction. J. exp. Psychol., 1956, 52, 167-176.

KLUGH, H. E. Speed of running in extinction as a function of differential goal box retention time. J. exp. Psychol., 1961, 61, 172-177.

LOGAN, F. A. Incentive. New Haven: Yale Univer. Press, 1960.

STANLEY, W. C., \& ROWE, M. I. Extinction by omission of food as a function of goal-box confinement. J. exp. Psychol., 1954, 48, 271-274.

\section{Note}

1. This research was supported in part by National Institute of Child Health and Human Development Research Grant HD 00949-02 to the first author. 